\title{
Correction to: Geniza Magical Documents
}

\author{
ORTAL PAZ-SAAR
}

Utrecht University, Utrecht, Netherlands

E-mail: o.p.saar@uu.nl

\section{Correction to: Jewish History https://doi.org/10.1007/s10835-019-09322-6}

The original article was published with an incomplete caption for fig. 1. Figure 1 with the correct caption appears on the next page. 


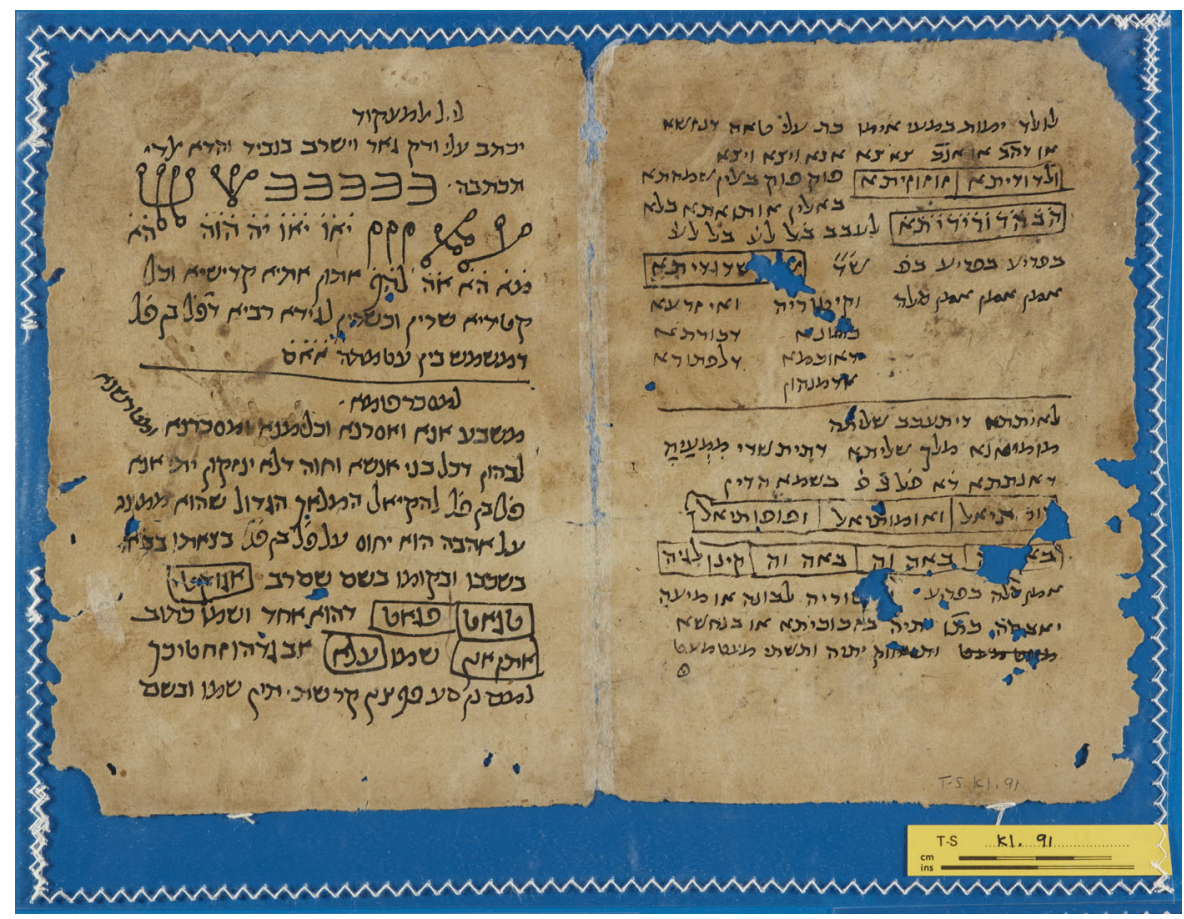

Figure 1. A fragment from a medieval handbook of magic containing recipes for various aims. Cambridge University Library T-S K1.91, fol. 2 recto. Reproduced by kind permission of the Syndics of Cambridge University Library.

Publisher's Note Springer Nature remains neutral with regard to jurisdictional claims in published maps and institutional affiliations.

Open Access This article is distributed under the terms of the Creative Commons Attribution 4.0 International License (http://creativecommons.org/licenses/by/4.0/), which permits unrestricted use, distribution, and reproduction in any medium, provided you give appropriate credit to the original author(s) and the source, provide a link to the Creative Commons license, and indicate if changes were made. 